\title{
A Review on Power Plant Maintenance and Operational Performance
}

\author{
Puvanesan Velayutham ${ }^{1}$, Firas Basim Ismail ${ }^{2}$ \\ ${ }^{1,2}$ Power Generation Unit, Institute of Power Engineering (IPE), Universiti Tenaga Nasional, 43000 \\ Kajang, Selangor, Malaysia
}

\begin{abstract}
This paper presents the power plant maintenance scheduling and particle swarm optimization (PSO) technique to ensure economical and reliable operation of power system. Initially problems related to the power plant maintenance scheduling in modern power systems are briefed, also explaining the need and importance of an optimum and reliable power plant maintenance system. It briefly describes the maintenance scheduling of power plant by application of PSO technique. This paper proposes power plant maintenance scheduling of a power system based on minimization of the objective function considering the economical and reliable operation of a power system while satisfying the crew/manpower and the load demand.
\end{abstract}

\section{Introduction}

Power demand has tremendously increased all over the world especially under the drastic development around the world. Power plants are classified as the important, core module of power systems, and are responsible for producing power to be transmitted and distributed to the end customers [1]. The reliability of the power plants and transmission lines in the electricity industry is highly concerned to ensure sufficient electricity is supplied to the customers [2]. If the power plants are not well taken care and is not reliable to be operated, a significant amount of damages would be possibly imposed to the society as a sequence of power shortage.

\section{Power plant maintenance}

Maintenance is the actions need to be taken continuously to ensure that a product provides reliable service. There are two types of maintenance called corrective and preventive. Corrective maintenance usually performed after a breakdown occurred. Meanwhile, preventive maintenance is performed to reduce the opportunity of failure of the respective system. Maintenance in the power industry is very crucial to ensure the power supply meet the customers' demand. Mulugeta Asaye Adale has illustrated issues faced by power plants with improper maintenance scheduling [4]. They also consider the length of the period for preventive maintenance for the equipment considering the cost and the reliability of the equipment [5]. The maintenance-scheduling problem consists on defining the time and period to stop the generating units for preventive maintenance to ensure the maintain the system is available, reliable and the general operation cost is reduced. 


\section{Maintenance practices and their relationship with the operational performance}

A study by Mulugeta [4] on Reykjane \& Nesjavellir power stations in Iceland on analysing the maintenance practices through benchmarking for power plants developed a model to improve the overall operational performances by searching for a best and optimum ways of maintenance practices. The primary focus of the study was to identify the best maintenance practices for Reykjanes power station [4]. In a five years' period, by benchmarking the power plant on average, used $13 \%$ emergency maintenance, $26 \%$ preventive maintenance, $41 \%$ predictive maintenance and $20 \%$ planned corrective maintenance while Nesjavellir power plant best performer used $14 \%, 13 \%, 71 \%$ and $2 \%$ of these practices respectively [4]. Combination of different maintenance practices were used by the benchmarked power plant due to few reasons such as age of the power plant, working condition of the generating units and the complexity of the plant $[1,3]$. Predictive maintenance was preferred in both power plants in providing a high reliable maintenance procedure to achieve high availability, minimize the down time and the repair time $[2,4,5]$. The power plant identifies for the study consisted of 22 maintenance and operation staff who regularly attended to the 12 turbines maintenance work [4]. These responsibilities consequently developed some skilful and knowledgeable operators and maintenance workers. Designing the machines for maintainability and increasing the spares stocks translates to reduced maintenance duration [8]. In addition, availability of the right spare items and materials in good condition is also very important to maintain power systems requirements if any breakdowns or damage happened to the generating units especially when it is operating during normal hours and to support both planned and unplanned outages.

According to Fernando and Gilberto, the availability of a power generating system depends on the reliability of the generating units and the maintenance policy [9]. Maintenance policy does not only affect the parts' repair time but also on the parts' reliability [9]. In their research on the availability and reliability analysis based on a method for each of the two$150 \mathrm{MW}$ gas turbines in a power plant in Brazil showed different results where by one presenting $99 \%$ and the other $96 \%$ availability, indicating differences in their systems installation and operation. They argued that the top management's concern is keeping the asset reliability and availability and reduce the maintenance and repair related cost [9]. Moubary has developed the Reliability Centred Maintenance (RCM) concept to ensure the continuity and reliability of the operation and performance of any physical assets whenever the users want to use it [10]. According to Smith and Hinchcliffe the maintenance policy is mainly focused on the predictive or preventive maintenance tasks to reduce the unexpected failures during the normal operation and ensure continuous supply of power to the customers [11].

Reliability and maintainability concepts were proposed by Eti to define an availability index expressed by the ratio of the mean time to failure to the sum of the mean time to failure plus the mean time to repair in order to increase the efficiency of maintenance and to bring down the maintenance cost [12]. The study stated that the data collected on field failures are particularly important because they are likely to provide the only estimates of the reliability and availability that incorporate the loadings, environmental and maintenance procedure effects found in practice. On both component and system levels such a database is valuable for predicting on site reliability and availability. A similar study by Olayika in Nigeria on implementation of preventive maintenance program in Egbin Thermal Power Plant revealed consistent results [13]. In conclusion the empirical results of the study found that systematic maintenance data collection, analysis and a continued reliability study could provide valuable information about the plant performance [14,15]. A study has been carried out in the Kenyan power generation sector to identify the operational performance of the plants based on the 
failure rates and the maintenance practices. The model could assist Power Plants operation managers in understanding the current performance of the plant and identification of actions to take to exceed identified business standards to improve performance $[16,17]$.

\section{Maintenance optimization}

One of the major criteria focused in the development of power system is the optimization of power plant scheduling. Production and maintenance scheduling is very important to run an effective operation process plants [19]. Improper and suboptimal maintenance schedule can increase the production costs and decreases the system reliability. Furthermore, a proper, optimum and systematic maintenance method can extend the period for the next failure and at the same time can balance the cost and risks in daily operation. An optimal power plant maintenance will increase the reliability of the operating system, minimizes the electricity generation cost and the lifetime of the power plant's generating units increases. Moreover, optimized maintenances schedule could potentially defer some capital expenditure for new plants and allow critical maintenance work to be performed [16]. In other words, an effective and efficient maintenance method plays a vital role for a power plant to operate effectively with high reliability and lower maintenance cost.

Power utilities spend billions of dollars per year for maintenance. Maintenance outage of generating units in power plant affects the reliability of system operation and the production cost of generating facilities. In the research conducted by Al-Najjar, he stated that Sweden spent about USD [23×10] $\wedge 9$ just for the maintenance and safety [16]. Due to improper maintenance activities the cost exceeds the generating equipment price and omission of maintenance. Furthermore, based on the research done by Mobley, about $28 \%$ of the total cost in a final product is consumed by the maintenance activities in an industry [17]. Other than that, the Department of Trade and Industry in the UK discovered that improper and unsafe maintenance costs the UK industry about USD [1.95×10] $\wedge 9$ a year [18]. The cost needs to spend for the maintenance purposes varies in every industry depending on its size of the industry and nature of the business, upkeep activities cost about $15 \%$ to $70 \%$ of the entire operational budget. Allocated budget for maintenance activities is considered the second major budget after the energy budget and it proves that systematic maintenance schedule in the electric utility system is one of the most important part of the overall operations scheduling problem. Power system units are kept in a good and reliable operating condition by performing regular and frequent preventive maintenance. The maintenance tasks for the power systems is often performed by the human beings who is very expert and create the maintenance schedule from the knowledge and experience gained during working in the field manually. In other words, there is no guarantee that the maintenance system produced is a reliable and systematic thus an optimal solution is not achieved. The purpose of an optimized maintenance scheduling is to identify the method of scheduled outages of generating units over a given period such that the amount of energy supplied to the customers is maintained [19]. This type of schedule is important mainly in a maintenance activity because will directly affects other planning activities [20]. Previously, few studies have been carried out on the development method of optimizing the maintenance schedule for power generations stations [21]. Earlier time, mathematical programming methods such as dynamic programming, integer programming, mixed-integer programming and the implicit enumeration logarithms have been used [19-22]. Recently, metaheuristic, a higher-level procedure or heuristic designed to find, generate or to select a heuristic that may provide a sufficiently better solution to an optimization problem, has been discovered, including genetic algorithm (GA), simulated annealing (SA), Tabu search (TS) dan Particle Swarm Optimization (PSO) [15]. 


\section{Particle swarm optimization techniques in power systems}

Currently to solve the global optimization problems, one of the modern algorithms method used is Particle Swarm Optimization (PSO) [23], and it applies the same principle as the previous methods. Therefore, PSO applies a simplified social model to solve an optimization problem, which for instance Zoologist might use to explain the individuals' movement within a group [24]. For the beginning, PSO initializes "particles" which is called as a population of random solutions each of which is defined. Every particle moves into a space, which is identified as a problem hyperspace at a random velocity. Once flew into the hyperspace, the particles will adjust its travelling speed dynamically according to the flying experience of itself and its colleagues [18,23]. Thereafter, until a global optimum solution is achieved, the PSO computation continuously update the position of the particles.

Among all the other methods, PSO application is easier to be used. This is because PSO application can identify a number solution with high quality immediately and has stable convergence characteristics [8,19-27]. Moreover, is robust in solving continuous non-linear optimization problems, and compared to other evolutionary algorithms, it is flexible, and the mechanism is well balanced to improve and adjust the global and local search capabilities [28]. However, PSO application seems to be very sensitive to the tuning of some of its weights or parameters [29]. Besides, sometimes PSO can also suffer from the lack of diversity amongst the particles, where it is possible to lead to a stagnation stage [19]. Consequently, although PSO has been a subject of an extensive research, there is a number of issues that need to be addressed to exploit the full potential of PSO in solving complex power system problems [29]. One of the objectives of this thesis is to contribute to this research area and developed a new improved hybrid PSO algorithm.

\section{Conclusion}

Nowadays the practical problems are becoming complex day by day. In order to maintain the optimal power system operation and provide continuous supply to the customer, an optimized maintenance system is required which is reliable and economic and can meet all the requirements [30]. We need to develop such an algorithm, which can successfully solve unimodal as well multimodal optimization problems [31]. PSO will be the most time efficient method to use when looking for a near optimal solution as the population size can be kept small. The present paper reviews some important of the power plant maintenance scheduling in order to have a well-maintained power system and the review on the development of PSO in optimizing the power plant maintenance scheduling.

The authors would like to express gratitude to Power Generation Unit, Institute of Power Engineering (IPE), Universiti Tenaga Nasional (UNITEN) and Tenaga Nasional Berhad (TNB) for providing research grant to carry out this research.

\section{References}

1. H. Sabouhi, A. Abbaspour, M. F. Firuzabad, P. Dehghanian, International Journal of Electrical Power \& Energy Systems, 79, 108-119, (2006).

2. A. Froger, M. Gendreau, J. E. Mendoza, E. Pinson, L. M. Rousseau, European Journal of Operational Research, (2015).

3. D.P Eygelaar, J.H. Lotter, van Vuuren, Electrical Power and Energy Systems, (2017).

4. M. A. Adale, Evaluation of maintenance management through benchmarking in geothermal Power Plant, (2009). 
5. R. Pascual, V. Meruane, and P.A Rey, Reliability Engineering and System Safety, 93, 144-151, (2009)

6. A. Smith, and G. Hinchcliffe, A gateway to world class maintenance, 45-286 (2004).

7. M. Eti, S. Ogaji, and S. Probert, Applied Energy 84, 202-201, (2007).

8. T. Wireman, The neglected pillar of TPM, (2000).

9. F. Jesus \& G. Francisco, Availability Analysis of Gas Turbines Used in Power Plants, 12, 211-213 (2009)

10. J. Moubray, Reliability-Centred Maintenance, (1997).

11. E. Valian, S. Mohanna, S. Tavakoli, International Journal of Artificial Intelligence \& Applications, 2, 36-43 (2011).

12. M.C Eti, S.O.T Ogaji, and S.D Probert, Applied Energy 83, 299-310, (2006).

13. O. Oyedepo, O. Fagbenle, Implementation of preventive maintenance programme in Nigeria Power Industry-Egbin Thermal Power Plants, (2011)

14. G.J Anders, Probability concepts in Electric Power Systems, (1990).

15. El-Amin, I. S. Duffuaa and M. Abbas, Electrical Power Systems Research, 54, 91-99, (2000).

16. B. Al-Najjar, Journal of Quality in Maintenance Engineering, 2, 4-20, (1996).

17. R. Mobley, An Introduction to Predictive Maintenance, (1990).

18. B. Rao, Profitable condition monitoring and diagnostic engineering management, 37-46, (1993).

19. M. Biondi, G. Sand, I. Harjunkoski, Computers and Chemical Engineering, 148-153 (2017).

20. Z. Yamayee, Sidenblad and M. Yoshimura, IEEEE Transactions on Power Apparatus and Systems, 330-338, (1983).

21. J. F. Dopazo, IEEE Transactions on Power Apparatus and Systems, 1537-1545, (1975).

22. A. Ahmad, Electric Machines and Power Systems, 501-513, (2000).

23. Escudero, L. F. Horton and J. E. Scheiderich, IEEE Winter Power Meeting, (1980).

24. E. R. Kennedy, Proceedings IEEE International, (1995).

25. J. Yellen, T. M. Al-khamis, S. Vermuri and L. Lemonidis, IEEE Transactions on Power Systems, 726-733, (1992).

26. S. Kumhar, M. Kumar, International Research Journal of Engineering and Technology (IRJET), (2016).

27. T. Logenthiran and D. Srinivasan, IEEE TENCON,1-6, (2009).

28. R.C Eberhan and Y. Shi, Proceedings of the IEEE Congress on Evolutionary Computation (CEC 2WO), (2000).

29. E. L. Silva, M. T. Schilling and M. C. Rafael, IEEE Transactions on Power System, 15, (2000).

30. K.P. Dahal, C.J Aldridge, R. Mc Donnald, Elsevier, 102, 21 (1999)

31. Y. Yare and G. K. Venayagamoorthy, iREP Symposium- Bulk Power System Dynamics and Control - VII, Revitalizing Operational Reliability, Charleston, (2007). 